\title{
Manufacture and Characterization of Mucoadhesive Buccal Films Based on Pectin and Gellan Gum Containing Triamcinolone Acetonide
}

\author{
Felipe Pereira Fernandes $\mathbb{D}^{1},{ }^{1}$ Amanda Campos Fortes, ${ }^{1}$ Said Gonsalves da Cruz Fonseca ${ }^{D},{ }^{2}$ \\ Jörg Breitkreutz, ${ }^{3}$ and Humberto Gomes Ferraz ${ }^{1}$ \\ ${ }^{1}$ Department of Pharmacy, Faculty of Pharmaceutical Sciences, University of São Paulo, São Paulo, Brazil \\ ${ }^{2}$ Department of Pharmacy, Faculty of Pharmaceutical Sciences, Federal University of Ceará, Fortaleza, CE, Brazil \\ ${ }^{3}$ Institute of Pharmaceutics and Biopharmaceutics, Heinrich Heine University Düsseldorf, Düsseldorf, Germany \\ Correspondence should be addressed to Felipe Pereira Fernandes; felipefernandes290@hotmail.com
}

Received 31 January 2018; Accepted 29 April 2018; Published 19 July 2018

Academic Editor: Karthikraj Rajendiran

Copyright (c) 2018 Felipe Pereira Fernandes et al. This is an open access article distributed under the Creative Commons Attribution License, which permits unrestricted use, distribution, and reproduction in any medium, provided the original work is properly cited.

\begin{abstract}
The treatment of canker sores can be quite compromised by the short period of the drug in the place of action. In this context, there is a need to develop drug dosage forms that allow more contact with the oral mucosa providing prolonged drug release. Therefore, the aim of this work was to obtain and characterize buccal films based on pectin and gellan gum in order to evaluate the potential use of these natural polymers in the production of pharmaceutical dosage forms for controlled release of TA in the oral mucosa. Using a $2^{3}$ full factorial design, eight formulations were prepared by solvent casting method. The raw materials and films were characterized using techniques such as FTIR, DSC, and TG. In addition, thickness, mechanical properties, mucoadhesive strength, swelling, drug content, and dissolution profile of the films were evaluated. The results of FTIR, DSC, and TG showed that new chemical species are not formed in the production of films, and that these dosage forms have an adequate thermal behavior. All formulation showed a high degree of swelling, good mechanical resistance and elasticity, and a good mucoadhesive strength as well as able to act as a controlled release system.
\end{abstract}

\section{Introduction}

The oral cavity connects the external environment to interior of the body and is subject to different types of pathologies that require local treatment, such as periodontal disease, gingivitis, oral candidiasis, halitosis, herpes, and canker sores [1]. Specifically in the case of canker sores, the treatment consists of mouthwash with antiseptics, as well as the application of ointments for oral use containing antiinflammatory drugs [2]. However, due to the short residence time of the drug at the site of action, this treatment can be greatly compromised, requiring multiple doses throughout the day [3].

For this reason, several buccal formulations like gels $[4,5]$, mucoadhesive tablets [6-8], patches, and buccal films [9-15] have been developed using polymers that allow the most direct contact with the mucosa and provide a prolonged release of the drug, reducing the need for administration of repeated doses $[10,16]$.

In particular, buccal films show greater accuracy and flexibility in relation to dose and better mechanical resistance when compared to other dosage forms. Besides, it can act as a controlled release system and can be easily removed in emergency cases [17, 18].

According to Patel et al. [19], films are flexible and elastic which provide greater comfort to patient. However, they are strong enough to resist breakage caused by movements of the mouth $[10,20]$. Due to these features, films can be used at night, during sleep, increasing adherence to treatment.

In this work, films were formulated using natural polymers, pectin (PEC) and gellan gum (GG). Triamcinolone acetonide (TA), a synthetic glucocorticoid, was used as a 
model drug, since it is used in long-acting relief of signs and symptoms of many oral inflammatory conditions, particularly canker sores $[2,21,22]$.

Pectin is a natural polysaccharide found in the cell wall of several plant species, mainly composed by alternating galacturonic acid, rhamnose residues, and some arabinan and/or galactan side chains. It presents both mucoadhesive and swelling properties and moreover can be used either alone or associated with natural or synthetic polymers in the designing of different drug delivery systems [23-25].

Gellan gum is an exocellular polysaccharide secreted from the bacterium Sphingomonas elodea and consists of repeating tetrasaccharide of glucuronic acid, rhamnose, and glucose $[26,27]$. It is widely used in the food industry due to its gelling properties [28].

Both polymers are nontoxic, biocompatible, and biodegradable and possess mucoadhesive properties which make them a promising material for pharmaceutical application [24, 29-32].

There are some studies about films using gellan $[33,34]$ and pectin singly [35-37], but the preparation of the films has some drawbacks such as the use of acids, organic solvents, or crosslinking agents.

Moreover, as far as we know, there are no works in the literature using GG and PEC together to the development of buccal films. Therefore, the aim of this work was to obtain, through a simple method, and characterize buccal films for evaluating the potential use of these natural polymers in the production of pharmaceutical forms for controlled release of TA in the oral mucosa.

\section{Materials and Methods}

2.1. Materials. Triamcinolone acetonide was kindly provided by Prati-Donaduzzi (PR, Brazil). The polysaccharides, low acetylated gellan gum (KELCOGEL ${ }^{\circledR}$ CG-LA type) and low esterified citrus pectin (GENU ${ }^{\circledR}$ Pectin USP-B type), were kindly donated by CP Kelco (SP, Brazil). Glycerol (GLY) (Synth Reagentes Ltda, SP, Brazil) was used as plasticizer.

2.2. Design of the Buccal Films. Buccal films were prepared by solvent casting technique [38]. First, the polymers and the drug $(100 \mathrm{mg})$ were dissolved in $100 \mathrm{ml}$ of water at $50^{\circ} \mathrm{C}$, using a magnetic stirrer at $150 \mathrm{rpm}$ for 12 hours. Then, the plasticizer was added and homogenized for 2 hours. Finally, $100 \mathrm{~g}$ of this solution was poured into a glass Petri dish and dried in a circulating oven air at $40^{\circ} \mathrm{C}$ for 24 hours, resulting in a thin film after solvent evaporation.

A $2^{3}$ full factorial design was used to evaluate the influence of independent variables-amounts (\%) of pectin, gellan, and glycerol at two levels-on the response of swelling, mechanical properties, and cumulative drug release after 1 and 10 hours (\%). This experimental design resulted in eight films formulations, which contained a fixed amount of the drug (Table 1).

2.3. Physicochemical Characterization. The isolated raw materials (TA, PEC, GG, and GLY) and the buccal films were subjected to Fourier transform infrared spectroscopy (FTIR),
TABle 1: Percentage $(w / v)$ of pectin, gellan gum, and glycerol in the polymer solutions used in the preparation of films.

\begin{tabular}{lccc}
\hline Film & PEC & GG & GLY \\
\hline F1 & 0.3 & 0.3 & 0.5 \\
F2 & 0.3 & 0.3 & 1 \\
F3 & 0.5 & 0.3 & 0.5 \\
F4 & 0.5 & 0.3 & 1 \\
F5 & 0.3 & 0.5 & 0.5 \\
F6 & 0.3 & 0.5 & 1 \\
F7 & 0.5 & 0.5 & 0.5 \\
F8 & 0.5 & 0.5 & 1 \\
\hline
\end{tabular}

differential scanning calorimetry (DSC), and thermogravimetry (TG).

The FTIR spectra (infrared spectrophotometer, Bruker Vertex-70, USA) were obtained, in an inert atmosphere $\left(\mathrm{N}_{2}\right)$, with a resolution of $4 \mathrm{~cm}^{-1}$ from the 4000 to $500 \mathrm{~cm}^{-1}$ region.

DSC curves were obtained using a DSC 7020 cell (Exstar, Japan), and the TG/DTG curves were taken with a TG/DTA 7020 thermobalance (Exstar, Japan) under a nitrogen flow and heating rate of $10^{\circ} \mathrm{C} \mathrm{min}^{-1}$. Highly pure indium (m.p., $156.6^{\circ} \mathrm{C} ; \Delta H_{\text {fus }}, 28.54 \mathrm{Jg}^{-1}$ ) was used to calibrate the DSC cell, and calcium oxalate was used to calibrate the thermobalance, under the same conditions as the samples.

2.4. Swelling. Swelling of the films was determined using a method described by Yang et al. [27]. The calculation to determine the percentage of swelling is shown in

$$
\text { Swelling }(\%)=\left(\frac{m 2-m 1}{m 1}\right) \times 100
$$

where $m 1$ and $m 2$ represent the mass of dry samples before and after immersion in the solution, respectively.

2.5. Disintegration. The disintegration was determined using a disintegrator (Ethik Technology, Brazil). Saline buffer (pH 6.8) at a temperature of $37 \pm 2^{\circ} \mathrm{C}$ was used as the test media. The buccal films $(n=3)$ were subjected at successive vertical immersion and the time until total disintegration was recorded.

2.6. Drug Content Uniformity. The drug content was determined using a method adapted from the United States Pharmacopeia [39]. A piece of each film $(n=5)$ equivalent to $1.5 \mathrm{mg}$ of drug was weighed, dissolved in ethanol, and transferred to a $25 \mathrm{ml}$ flask. The sample was subjected to ultrasound for 60 minutes to ensure complete solubilization of the active. Then, the flask volume was completed, and an aliquot was removed and filtered through a $0.20 \mu \mathrm{m}$ filter aid Minisart RC 25 (Sartorius, Göttingen, Germany). The amount of drug in the resulting solution was determined by UV spectrophotometer DU-640 (Beckman Coulter, USA) at a wavelength of $242 \mathrm{~nm}$. 
2.7. Film Thickness. Micrometer screw (Mitutoyo, Neuss, Germany) was used to determine film thicknesses of samples. Five points were measured for each formulation.

2.8. Folding Endurance. Folding endurance of each film ( $n$ $=3$ ) was determined by folding the film, $180^{\circ}$ in the same place, up to a maximum 300 times or until the film breaking.

2.9. Mechanical Properties. The mechanical properties as puncture strength and elongation to break were determined according to Preis et al. [38].

The system started recording force and displacement of the probe when having contact to the sample. Using a probe of area $18.10 \mathrm{~mm}^{2}$, the measure of puncture strength and elongation percentage was calculated.

$$
\text { Puncture strength }=\frac{\text { Force }(\mathrm{N})}{\text { Area }\left(\mathrm{mm}^{2}\right)},
$$

Elongation to break $=\left[\left(\sqrt{\left(a^{2}+b^{2}\right)}+\frac{r}{a^{\prime}}\right)-1\right] \times 100$,

where $a^{\prime}$ is the initial length of the film sample that is not punctured by the probe, $b$ is the penetration depth/vertical displacement by the probe, and $r$ is the radius of the probe.

2.10. Determination of Mucoadhesive Strength. Mucoadhesion properties were assessed by adapting the methodology used by Sathe et al. (2015). The mucoadhesive strength of each formulation $(n=3)$ was calculated.

$$
\text { Mucoadhesive strength }\left(\mathrm{N} / \mathrm{cm}^{2}\right)=\frac{M \times G}{A}\left(\mathrm{~cm}^{2}\right) \text {, }
$$

where $M$ is the weight required for detachment in $\mathrm{kg}, G$ is the acceleration due to gravity $\left(9.81 \mathrm{~m} / \mathrm{s}^{2}\right)$, and $A$ is the area of the film exposed.

2.11. Dissolution Profile. In vitro dissolution studied was performed, in triplicate, using a paddle over disk apparatus (USP 5). The buccal films were cut into circular patches (equivalent to $8 \mathrm{mg}$ of drug), placed over the disk, and covered with a polyester mesh. This apparatus was settled in the bottom of the dissolution vessel, containing $900 \mathrm{ml}$ of saline buffer (pH 6.8) at $37 \pm 1^{\circ} \mathrm{C}$. The dissolution test was carried out in a D-800 Logan dissolution tester (Logan Instruments Corp, USA) with paddle speed of $75 \mathrm{rpm}$. At prespecified time intervals, $5 \mathrm{ml}$ of aliquots was withdrawn by filtration $(0.45 \mu \mathrm{m})$ and equal volume of fresh prewarmed medium was replaced in the vessel. The absorbance of aliquots was taken at $242 \mathrm{~nm}$ by UV spectrophotometer DU-640 (Beckman Coulter, USA), and percentage of drug released to the dissolution medium was calculated.

The mechanism of drug release was analyzed using different mathematical models (Korsmeyer-Peppas, Higuchi, firstorder, and Hixson-Crowel) by the DDSolver software. All the experiments were performed in triplicate. Results are expressed as mean $\pm \mathrm{SD}$. ANOVA and $t$-test were used to determine statistical significance of studies. Differences were considered to be significant for values of $p<0.05$.

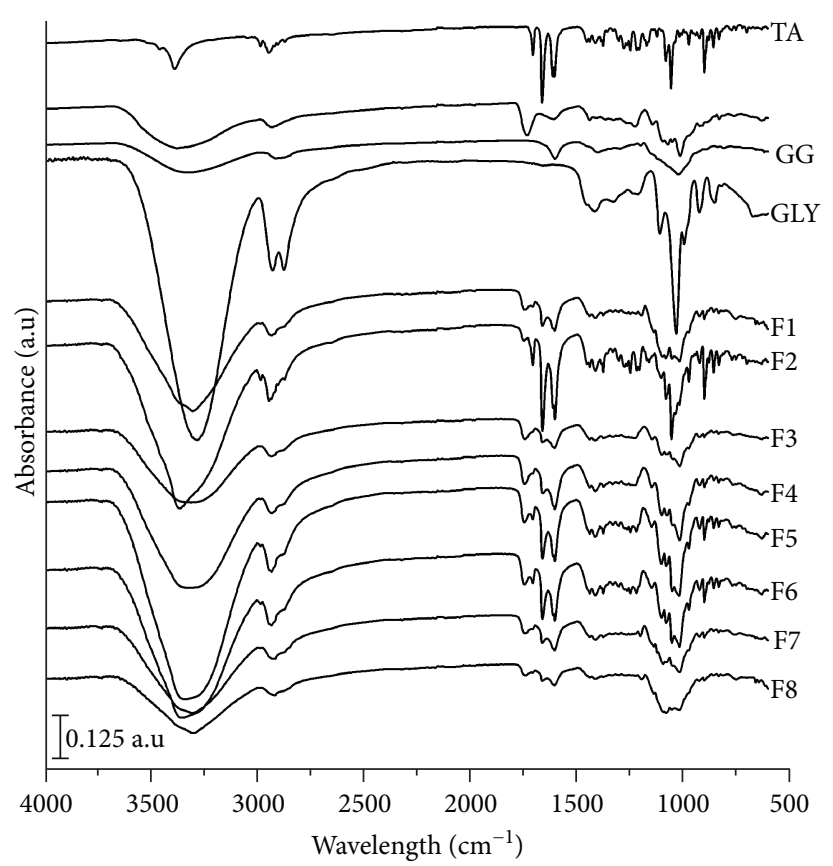

FIgURE 1: Infrared spectra of isolated raw materials (TA, PEC, GG, and GLY) and the buccal films (F1-F8).

\section{Results and Discussion}

3.1. Infrared Spectroscopy (FTIR). Figure 1 shows infrared spectra of isolated raw materials (TA, PEC, GG, and GLY) and the buccal films (F1-F8). The bands observed to TA included the $\mathrm{OH}$ group in the range of $3390-3462 \mathrm{~cm}^{-1}$, $\mathrm{C}=\mathrm{O}$ bands between 1500 and $1750 \mathrm{~cm}^{-1}, \mathrm{C}=\mathrm{C}$ bands in the range $1660-1600 \mathrm{~cm}^{-1}, \mathrm{C}-\mathrm{H}$ stretching of $\mathrm{sp}^{3}$ and $\mathrm{sp}^{2}$ carbons in the range of 3100 and $2900 \mathrm{~cm}^{-1}$, and $\mathrm{C}-\mathrm{O}$ stretching at $1200 \mathrm{~cm}^{-1}$ [40].

The characteristic FTIR peaks of pectin were a broad band at $3100-3550 \mathrm{~cm}^{-1}$ which was assigned to $-\mathrm{OH}$ stretching, a band between $2900-3000 \mathrm{~cm}^{-1}$ due to the stretching vibration of methyl group of methyl ester. Bands between 1756 and $1530 \mathrm{~cm}^{-1}$ assigned to the $\mathrm{C}=\mathrm{O}$ stretching vibration of methyl-esterified carboxylic groups and vibrations of the carboxylate (-COO-) group, respectively. The absorption bands at 1220 and $1008 \mathrm{~cm}^{-1}$ corresponded to ether $(\mathrm{R}-\mathrm{O}-\mathrm{R})$ and $\mathrm{C}-\mathrm{C}$ bond in the ring structure of pectin molecules. Weak symmetric carbonyl stretching vibrations were observed in the range of $800-$ $1000 \mathrm{~cm}^{-1}[36,41]$.

The spectra of GG show a broad absorption band due to free $\mathrm{OH}$ group in the range of $3000 \mathrm{~cm}^{-1}$ and $3500 \mathrm{~cm}^{-1}$; a shoulder around $2900 \mathrm{~cm}^{-1}$ can be attributed to C-H stretch of alkane. Further, the spectra show bands in the range of $1600 \mathrm{~cm}^{-1}$ and $1400 \mathrm{~cm}^{-1}$ which can be ascribed to $\mathrm{C}-\mathrm{O}$ stretching of carboxylate ion. The band around $1000 \mathrm{~cm}^{-1}$ can be attributed to C-O stretch of carboxylic acid $[26,33]$.

Glycerol showed bands similar to the other components of the film, intense absorption band in the region of 3550$3100 \mathrm{~cm}^{-1}$ corresponding to the vibration of the $\mathrm{OH}$ group of alcohol, an absorption band around 1250 to $900 \mathrm{~cm}$ 


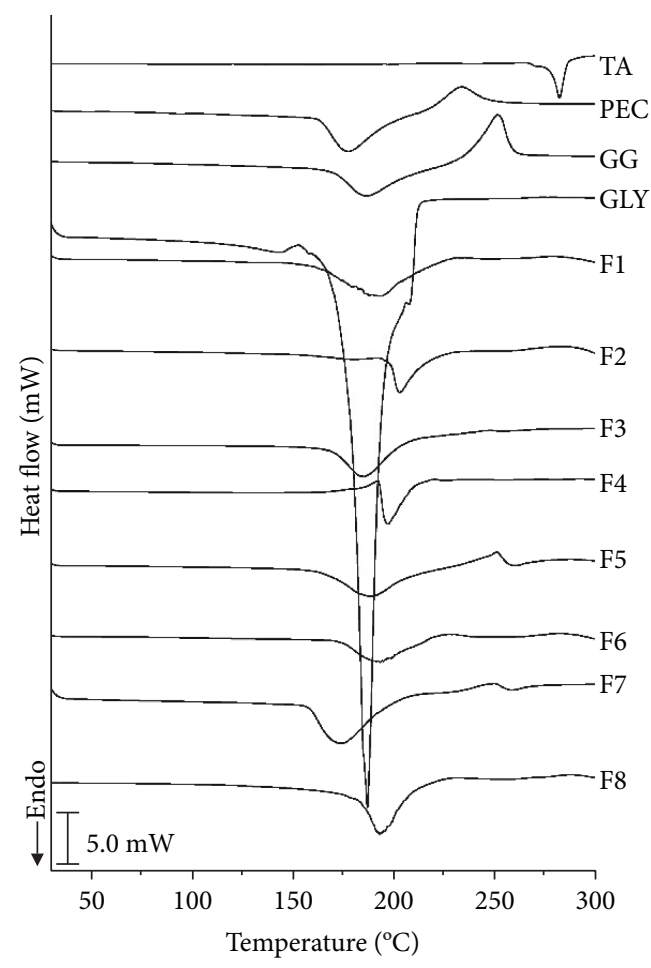

(a)

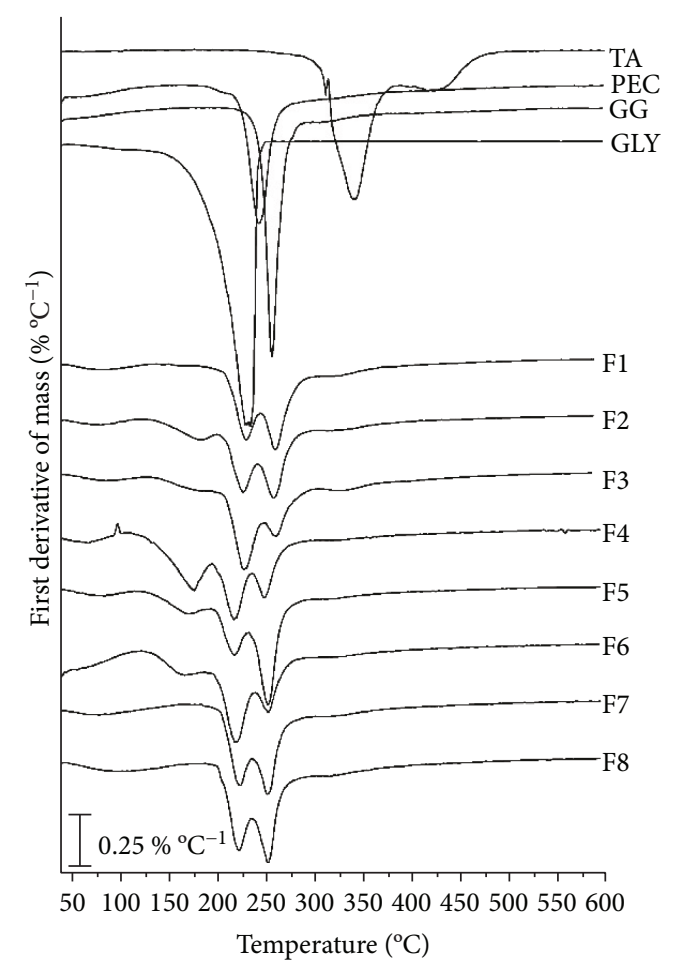

(b)

Figure 2: (a) DSC curves of isolated raw materials (TA, PEC, GG, and GLY) and the buccal films (F1-F8). (b) DTG of isolated raw materials (TA, PEC, and GG) and the buccal films.

strong intensity due to the stretching of $\mathrm{C}-\mathrm{O}$ bond, and a band at $2950 \mathrm{~cm}^{-1}$ which corresponds to $\mathrm{CH}$ stretching [42].

The FITR of the films showed the maintenance of characteristic bands of the raw materials. Only the band around $3500-3000 \mathrm{~cm}^{-1}$ shows quite intense, but this is due to the presence of residual water in the formulations. The absence of new bands in the FTIR shows that the components of the films do not react between them forming new chemical species [32].

3.2. Thermal Analyses. DSC curves (Figure 2(a)) show an endothermic spike for TA which corresponds with the melting point at $284.6^{\circ} \mathrm{C}$ and is indicative of a crystalline anhydrous state for TA. The DSC curves for the GG and PEC are quite similar. Both have two characteristic peaks, around $190-200^{\circ} \mathrm{C}$ assigned depolymerization of the polymer chains and a peak around $240-250^{\circ} \mathrm{C}$ attributed to degradation releasing common organic compounds in the thermal decomposition of natural polymers such as $\mathrm{CO}_{2}, \mathrm{CO}$, and $\mathrm{H}_{2} \mathrm{O}[25,32]$.

The DSC curves to films show no major differences in the curves presented for raw materials. The absence of a sharp endothermic peak corresponding to the melting point of the TA might be due to the conversion of crystalline drug to amorphous or disordered crystalline phase in the polymeric matrix [18].

DTG curve of TA (Figure 2(b)) shows that thermal degradation occurred only after $290^{\circ} \mathrm{C}$, in two steps, with the first occurring in the range of $290-350^{\circ} \mathrm{C}$ and the second occurring in the range of $350-450^{\circ} \mathrm{C}$. These results are in accordance with the published data from da Silva-Junior et al. [43]. DTG curves to GG and PEC show peaks between 230 and $250^{\circ} \mathrm{C}$ representing the degradation temperatures of these polymers $[44,45]$. The mass loss profile of the films is similar to raw material. It shows a peak near $100^{\circ} \mathrm{C}$, indicates loss of water, and peaks around $200-250^{\circ} \mathrm{C}$, indicating the degradation of polymers and plasticizer. Nevertheless, after the temperature of degradation of the polymers, the films continue to lose mass, but more slowly. It happens due to the elimination of carbonaceous material and of presence of TA in the polymeric film.

3.3. Film Properties. Swelling capacity is one of the most important features to application in polymeric drug delivery systems because it exerts an important effect on the release kinetics of drug incorporated in the films. Furthermore, it is directly related with mucoadhesivity, since the bioadhesive sites in the polymers chain are exposed during the swelling process when the absorption of the medium by the polymers happens [46].

The swelling polymer mechanisms can be described in three main steps. Initially, the adsorption on the surface of the medium occurs. Second, due to saturation of the surface, the molecules tend to migrate into the matrix up to the linking polar groups weakening the intermolecular hydrogen bonds, which leads to an expansion of the chains. Third, the spacing of the chains provides the generation spaces in the matrix which facilitates the penetration of water or other medium used [47]. 
TABle 2: Properties of buccal films (mean $\pm \mathrm{SD}, n=3)$ : percentage of swelling (\%), drug content (\%), thickness (mm), force (N), puncture strength $\left(\mathrm{N} / \mathrm{mm}^{2}\right)$, elongation break $(\%)$, and mucoadhesive strength $\left(\mathrm{N} / \mathrm{cm}^{2}\right)$.

\begin{tabular}{lccccccc}
\hline Film & $\begin{array}{c}\text { Swelling } \\
\%\end{array}$ & $\begin{array}{c}\text { Drug content } \\
\mathrm{Q} \%\end{array}$ & $\begin{array}{c}\text { Thickness } \\
\mathrm{mm}\end{array}$ & $\begin{array}{c}\text { Force } \\
\mathrm{N}\end{array}$ & $\begin{array}{c}\text { Puncture strength } \\
\mathrm{N} / \mathrm{mm}^{2}\end{array}$ & $\begin{array}{c}\text { Elongation to break } \\
\%\end{array}$ & $\begin{array}{c}\text { Mucoadhesive strength } \\
\mathrm{N} / \mathrm{cm}^{2}\end{array}$ \\
\hline F1 & $320.53 \pm 1.08$ & $109.60 \pm 1.80$ & $0.119 \pm 0.016$ & $12.58 \pm 0.11$ & $0.69 \pm 0.006$ & $25.53 \pm 5.53$ & $3.49 \pm 0.05$ \\
F2 & $298.93 \pm 0.53$ & $103.60 \pm 4.19$ & $0.148 \pm 0.015$ & $10.66 \pm 3.24$ & $0.59 \pm 0.179$ & $35.98 \pm 2.42$ & $3.68 \pm 0.03$ \\
F3 & $442.11 \pm 2.73$ & $110.90 \pm 0.13$ & $0.166 \pm 0.012$ & $26.35 \pm 9.38$ & $1.45 \pm 0.518$ & $42.15 \pm 2.05$ & $5.30 \pm 0.07$ \\
F4 & $438.99 \pm 1.74$ & $109.30 \pm 0.22$ & $0.242 \pm 0.018$ & $21.07 \pm 1.99$ & $1.16 \pm 0.110$ & $49.68 \pm 9.11$ & $5.50 \pm 0.06$ \\
F5 & $482.99 \pm 9.04$ & $97.37 \pm 1.85$ & $0.205 \pm 0.029$ & $31.79 \pm 2.95$ & $1.75 \pm 0.162$ & $39.59 \pm 5.01$ & $5.47 \pm 0.11$ \\
F6 & $480.12 \pm 7.37$ & $103.37 \pm 1.25$ & $0.225 \pm 0.025$ & $21.17 \pm 3.30$ & $1.39 \pm 0.182$ & $40.93 \pm 2.06$ & $5.74 \pm 0.06$ \\
F7 & $540.99 \pm 3.35$ & $102.01 \pm 0.55$ & $0.233 \pm 0.027$ & $48.57 \pm 12.79$ & $2.68 \pm 0.707$ & $31.78 \pm 10.14$ & $7.31 \pm 0.07$ \\
F8 & $572.70 \pm 2.16$ & $103.94 \pm 1.90$ & $0.222 \pm 0.021$ & $48.07 \pm 13.13$ & $2.66 \pm 0.725$ & $44.00 \pm 13.15$ & $7.57 \pm 0.07$ \\
\hline
\end{tabular}

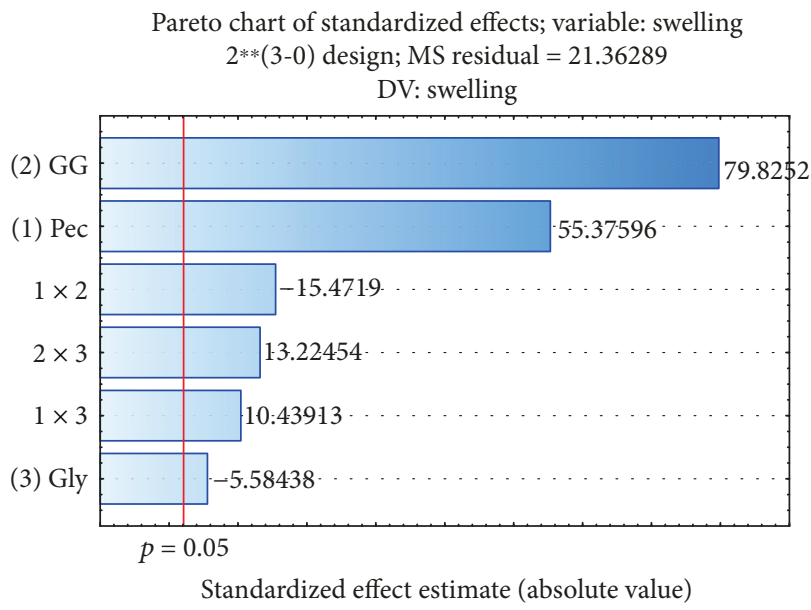

(a)

Pareto chart of standardized effects; variable: puncture $2^{* *}(3-0)$ design; MS residual $=0.1706149$ DV: puncture

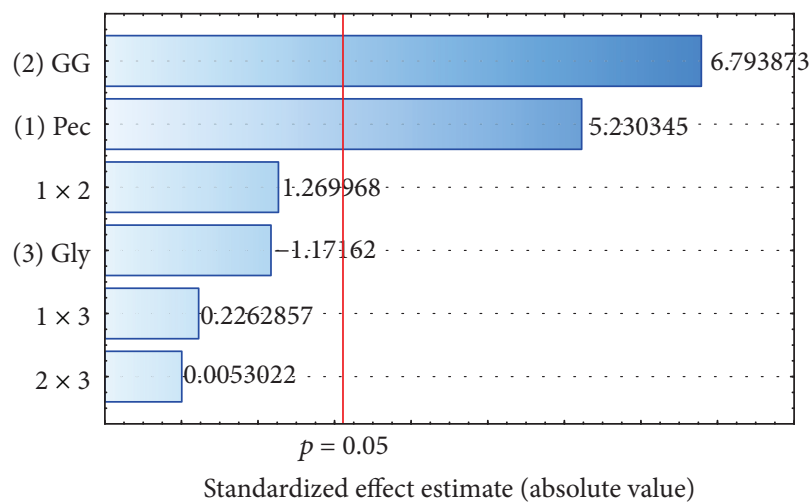

(c)
Pareto chart of standardized effects; variable: force $2 * *(3-0)$ design; MS residual $=55.89498$ DV: force

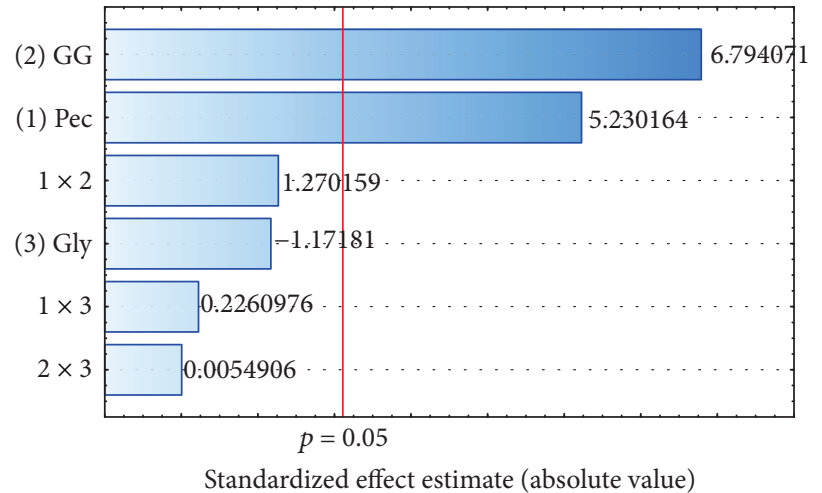

(b)

Pareto chart of standardized effects; variable: elongation $2 * *(3-0)$ design; MS residual $=51.52238$

DV: elongation

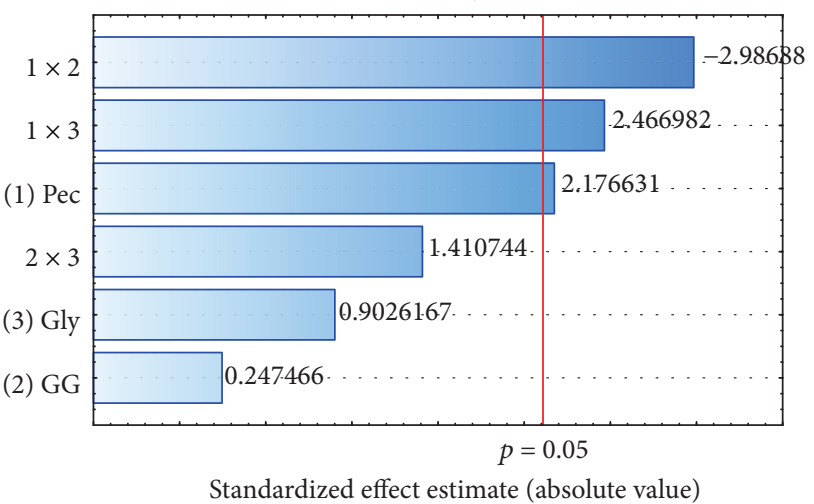

(d)

FIGURE 3: Pareto charts to determine the influence of the constituents in the buccal film properties as a swelling (a), force (b), puncture strange (c), and elongation to break (d).

Table 2 shows that the swelling percentage of the films was greater than $250 \%$ and it increased, proportionally, with the amount of polymer present in each formulation. This water absorption by the films is due to the formation of hydrogen bonds and the strong hydrophilic characteristics of carboxylic and hydroxyl groups present in the structures of polymers and plasticizer. PEC and GG are hydrophilic polymers that in $\mathrm{pH}$ around 7 , the carboxyl groups remain in the ionized form, which increases the hydrophilicity [32].

Figure 3(a) indicates that all the components of the formulations have an effect on the swelling of the films, wherein the gellan gum is the component with greater 


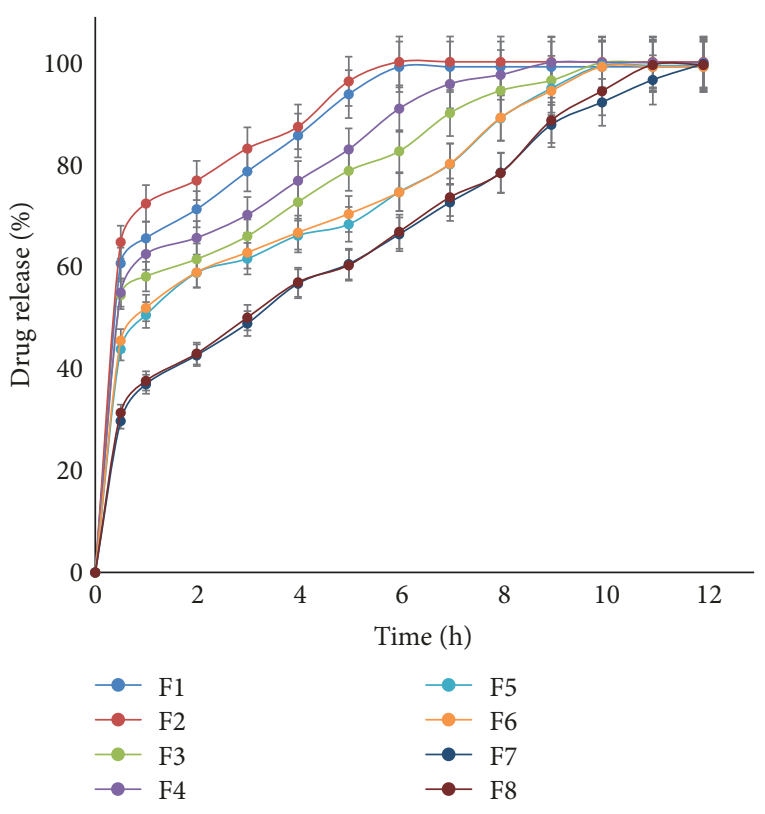

FIgURE 4: Dissolution profile of triamcinolone acetonide (TA) from buccal films consisting of gellan and pectin in various proportions.

influence in this property. However, glycerol, a hydrophilic plasticizer, that increases the space between the polymer chains also have positive effects either alone or interact with each other.

Regarding disintegration, all formulations showed disintegration time exceeding 8 hours. Results are quite satisfactory, since a drug delivery system designed for oral administration should resist the action of saliva, the tongue movements, and swallowing, thus allowing a more prolonged contact of the drug with its site of action.

Besides, the results of disintegration and swelling indicated that even without the addition of crosslinking agents, films retained their structure for a long period. These properties would hardly be achieved in films produced with the polymers isolated in the absence of crosslinking [48]. The similar structures of PEC and GG appear to be determinant to explain their synergistic interaction as it allows the development of an intermolecular bonding of these polysaccharides.

Drug content was satisfying for all formulations. The low standard deviations led to the conclusion that the drug was homogeneously distributed in the formulations. Table 2 shows the values of the mechanical properties. It is observed that generally when there is a larger amount of polymers in the formulation, the greater the strength and flexibility of the film. However, in formulations containing the same proportion of polymers but with different amounts of glycerol, films having more plasticizers are more fragile and have greater elasticity.

All films have an acceptable thickness (between $50 \mu \mathrm{m}$ and $1 \mathrm{~mm}$ ) for use as buccal device. Regarding the folding endurance, the F1 and F2 did not show good resistance. The F1 values were $120 \pm 12$ and for F2 were $90 \pm 9$ times, and all the other formulations did not break even after being folded up by more than 300 times. This is highly desirable because it would not allow easy dislocation of the films from the site of application or breaking of film during administration.

Figures 3(b)-3(d) show the influence of the components of the films in mechanical properties. It is noted that for force measurements Figure 3(b) and strength puncture Figure 3(c), GG and PEC separately have a positive effect; however, GG has a slightly larger positive effect. In relation to elongation Figure 3(d), the interactions between PEC and GG and PEC and GLY are the factors that influence this property. Glycerol, due to the increasing distance between the polymer chains, decreases the resistance of the films making them more fragile, but increases the elongation percentage of the formulations.

Due to the presence of hydroxyl and carboxylic groups in the polymer constituents of the films, all the formulations showed good mucoadhesion strength values. The hydrophilic groups present in the polymers bind to the mucin through hydrogen bonds; in addition, the presence of glycerol facilitates swelling and increases the distance between the polymer chains; consequently, this higher flexibility can improve the interpenetration and entanglement of bioadhesive polymer chains with mucous polymer (mucin), leading to the strengthening of mucoadhesive interactions. It can be seen that F1 and F2 have the smaller amounts of polymers; therefore, they have the lowest values of mucoadhesion.

The F7 and F8 formulations showed the greatest mucoadhesion values; however, a very high adhesive strength can make the removal of the attached device in the oral cavity difficult, which might cause discomfort to the patient.

3.4. Dissolution Profile. The dissolution profiles of TA from GG/PEC films (Figure 4) show that different formulations exhibited different times of total drug release. Initially, all the films had a burst effect. This effect can be explained due to a part of the drug that is only adsorbed on the polymer matrix, because the drug migrates to the surface of the film during the drying process. The burst effect is greater in formulations containing smaller amount of polymer; due to the fact that the polymeric film has fewer layers, the drug can easily migrate to the surface [49].

Formulations with higher amount of glycerol demonstrated a greater percentage of release, since this substance is hydrophilic and possesses a low molecular weight, promoting the relaxation of polymer chains during the initial of the swelling process, which originates a structure with new channels throughout the matrix, facilitating the diffusion of the drug $[32,50]$.

Figure 5(a) shows the influence of the components of the films in the TA release profile. During the early drug release, there is an influence of glycerol due to its hydrophilic groups interacting with the polymer through hydrogen bonds. However, being a highly hydrophilic substance, glycerol dissolves in the medium, decreasing its interaction with the other components of the film in the end of dissolution [51, 52].

GG and PEC also influence the TA release rate. This occurs because GG forms gels in aqueous solution, in the 


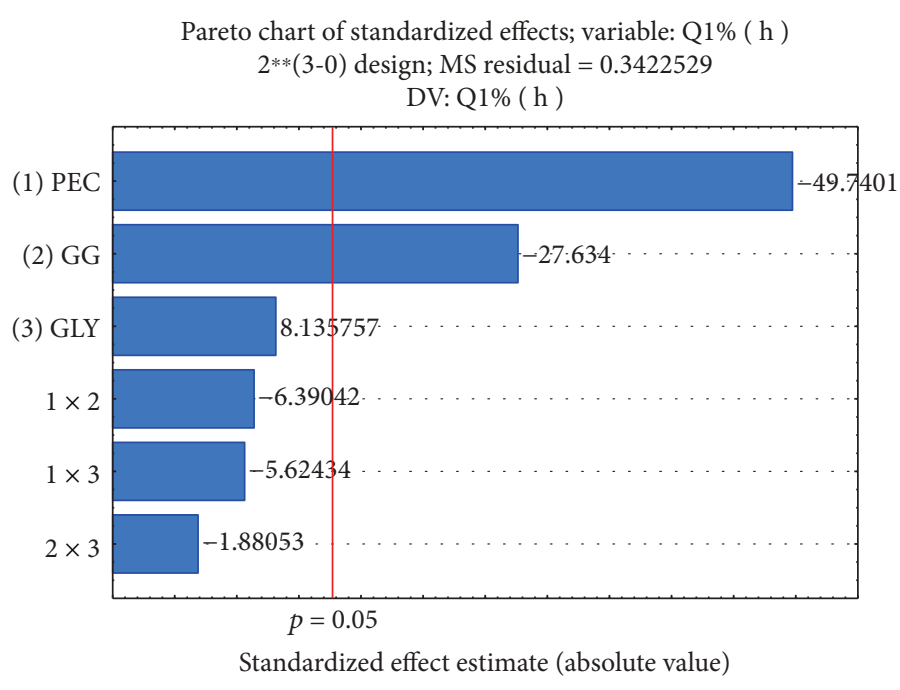

(a)

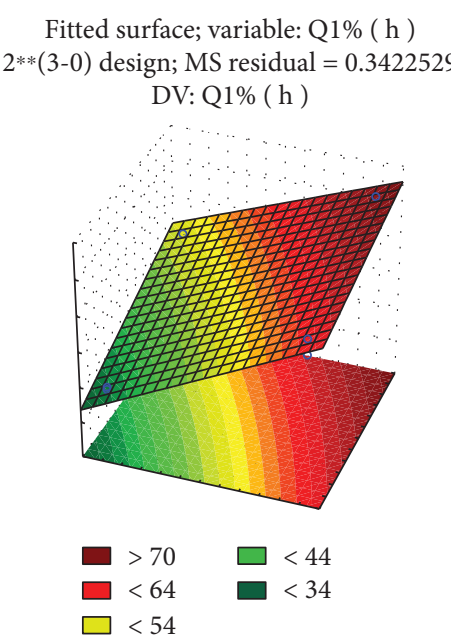

(b)

Figure 5: Pareto charts (a) and surface area (b) to determine the influence of the constituents of the buccal films in the dissolution of TA in predetermined times.

TABLe 3: Values of coefficient of determination $\left(r^{2}\right)$ for different mathematical models applied the release of TA from the buccal films.

\begin{tabular}{lccrr}
\hline Film & Higuchi $\left(r^{2}\right)$ & First-order $\left(r^{2}\right)$ & Hixson-Crowel $\left(r^{2}\right)$ & \multicolumn{2}{c}{ Korsmeyer-Peppas } \\
$\left(r^{2}\right)$ & $\mathbf{0 . 9 6 6 9}$ \\
\hline F1 & 0.7778 & 0.8309 & 0.7200 & $\mathbf{0 . 1 9 6 3}$ \\
F2 & 0.7008 & 0.8482 & 0.7189 & $\mathbf{0 . 9 9 5 5}$ \\
F3 & 0.7798 & 0.7411 & 0.6523 & $\mathbf{0 . 9 7 7 6}$ \\
F4 & 0.7713 & 0.7949 & 0.6953 & $\mathbf{0 . 9 8 8 3}$ \\
F5 & 0.8668 & 0.7462 & 0.6451 & $\mathbf{0 . 9 8 8 3}$ \\
F6 & 0.8477 & 0.7248 & 0.6302 & $\mathbf{0 . 1 9 7 4}$ \\
F7 & 0.9698 & 0.9044 & 0.8900 & $\mathbf{0 . 1 9 7 4}$ \\
F8 & 0.9704 & 0.8902 & 0.8618 & $\mathbf{0 . 1 9 7 9}$ \\
\hline
\end{tabular}

presence of salts, independent of $\mathrm{pH}$, and due to its double helix structure, that in aqueous medium forms "clusters," a kind of crosslinking, between the chains of this polymer, slowing down the release of drug [30, 31, 53]. However, pectin forms stronger gels at $\mathrm{pH}$ less than 3 [54].

During the dissolution test, the amount of polymer in the film is the main factor controlling the drug release. It can be observed in Figure 5(b) that formulations, which showed a higher release time of TA, were the films that contained larger amount of polymers.

Indeed, erosion, diffusion, and swelling of the polymeric matrices are the mechanisms by which these systems can control the release of drugs. In general, when the matrix structures have been exposed to the dissolution medium (or biological fluid), they can maintain their structure constant during the dissolution process or may suffer swelling phenomenon and subsequently erosion $[55,56]$. In the case of buccal films, they maintained their structure throughout the dissolution test, suggesting that swelling and diffusion are the factors that influence drug release.

Despite the complexity of the phenomena involved in drug release from hydrophilic matrix systems, some well- known models are used extensively to examine the release of active substance from such systems.

Table 3 shows the kinetic model most suitable to represent the release of TA from the buccal films. The model that best fitted the release data was evaluated by correlation coefficient $\left(r^{2}\right)$.

The mathematical treatment of the dissolution profiles showed that the most appropriate model to describe the kinetics of dissolution for all the formulations developed was the Korsmeyer-Peppas. This model is generally used to analyze the release of drug from polymeric dosage forms where the release mechanism is not well known or when more than one type mechanism that acts in the drug delivery. In the case of the buccal films developed, the transport of drug obeys the Fick laws (diffusion) because the release exponent is less than $0.5[32,57,58]$.

\section{Conclusions}

In this work, new buccal films based GG and PEC were successfully obtained through a simple method without the use of crosslinking agents, acids, or organic solvents. 
All formulations showed a high degree of swelling, good mechanical resistance and elasticity, and good mucoadhesive strength, and they were able to act as a controlled release system, controlling the release of TA for a period exceeding 8 hours in some cases.

However, formulations F1 and F2 showed the smallest value for all measurements and proved to be more brittle and have a low mechanical strength. Films F7 and F8 showed the highest values in all parameters, but they are not the best formulations, because of its high degree of swelling, low flexibility, and its high mucoadhesive strength which can bring discomfort to the patient.

Thus, the best films were F3, F4, F5, and F6. These formulations have intermediate values of polymers and good characteristics for an act as mucoadhesive release system, because they can release the drug gradually further and they can serve as a mechanical protection.

The results showed that only the interaction between hydrophilic polymers is sufficient to obtain films with adequate characteristics for use as drug release devices. This opens the way for future research for the production of films without the use of organic solvents and crosslinking agents, making the manufacturing easier and obtaining a safer final product to the patient.

\section{Data Availability}

The data used to support the findings of this study are available from the corresponding author upon request.

\section{Conflicts of Interest}

The authors declare that they have no conflicts of interest.

\section{Acknowledgments}

The authors of this paper thank Dr. Nágila Ricardo, from the Department of Chemistry of the Federal University of Ceará, for the provision of infrared equipment for conducting the tests. This work had the financial support of CAPES (Proc. 6364/15-2) and FAPESP agencies.

\section{References}

[1] C. Paderni, D. Compilato, L. I. Giannola, and G. Campisi, "Oral local drug delivery and new perspectives in oral drug formulation," Oral Surgery, Oral Medicine, Oral Pathology, Oral Radiology, and Endodontics, vol. 114, no. 3, pp. e25-e34, 2012.

[2] M. Rioboo Crespo and A. Bascones Martínez, "Aftas de la mucosa oral," Avances en Odontoestomatologia, vol. 27, no. 2, pp. 63-74, 2011.

[3] V. Hearnden, V. Sankar, K. Hull et al., "New developments and opportunities in oral mucosal drug delivery for local and systemic disease," Advanced Drug Delivery Reviews, vol. 64, no. 1, pp. 16-28, 2012.

[4] V. K. Rai, N. P. Yadav, P. Sinha et al., "Development of cellulosic polymer based gel of novel ternary mixture of miconazole nitrate for buccal delivery," Carbohydrate Polymers, vol. 103, pp. 126-133, 2014.
[5] J. Xu, S. Strandman, J. X. X. Zhu, J. Barralet, and M. Cerruti, "Genipin-crosslinked catechol-chitosan mucoadhesive hydrogels for buccal drug delivery," Biomaterials, vol. 37, pp. 395404, 2015.

[6] B. Parodi, E. Russo, P. Gatti, S. Cafaggi, and G. Bignardi, "Development and in vitro evaluation of buccoadhesive tablets using a new model substrate for bioadhesion measures: the eggshell membrane," Drug Development and Industrial Pharmacy, vol. 25, no. 3, pp. 289-295, 1999.

[7] S. Mohammadi-Samani, R. Bahri-Najafi, and G. Yousefi, "Formulation and in vitro evaluation of prednisolone buccoadhesive tablets," Il Farmaco, vol. 60, no. 4, pp. 339-344, 2005.

[8] Y. Ikeuchi-Takahashi, M. Sasatsu, and H. Onishi, "Evaluation of matrix type mucoadhesive tablets containing indomethacin for buccal application," International Journal of Pharmaceutics, vol. 453, no. 2, pp. 454-461, 2013.

[9] R. M. Obaidat, A. Bader, W. al-Rajab, G. Abu Sheikha, and A. A. Obaidat, "Preparation of mucoadhesive oral patches containing tetracycline hydrochloride and carvacrol for treatment of local mouth bacterial infections and candidiasis," Scientia Pharmaceutica, vol. 79, no. 1, pp. 197-212, 2011.

[10] A. Abruzzo, F. Bigucci, T. Cerchiara, F. Cruciani, B. Vitali, and B. Luppi, "Mucoadhesive chitosan/gelatin films for buccal delivery of propranolol hydrochloride," Carbohydrate Polymers, vol. 87, no. 1, pp. 581-588, 2012.

[11] J. O. Morales and J. T. McConville, "Manufacture and characterization of mucoadhesive buccal films," European Journal of Pharmaceutics and Biopharmaceutics, vol. 77, no. 2, pp. 187199, 2011.

[12] S. Singh, S. Jain, M. S. Muthu, S. Tiwari, and R. Tilak, "Preparation and evaluation of buccal bioadhesive films containing clotrimazole," AAPS PharmSciTech, vol. 9, no. 2, pp. 660667, 2008.

[13] S. Yehia, O. el-Gazayerly, and E. Basalious, "Fluconazole mucoadhesive buccal films: in vitro/in vivo performance," Current Drug Delivery, vol. 6, no. 1, pp. 17-27, 2009.

[14] C. Cavallari, A. Fini, and F. Ospitali, "Mucoadhesive multiparticulate patch for the intrabuccal controlled delivery of lidocaine," European Journal of Pharmaceutics and Biopharmaceutics, vol. 83, no. 3, pp. 405-414, 2013.

[15] M. Jug, I. Kosalec, F. Maestrelli, and P. Mura, "Development of low methoxy amidated pectin-based mucoadhesive patches for buccal delivery of triclosan: effect of cyclodextrin complexation," Carbohydrate Polymers, vol. 90, no. 4, pp. 1794-1803, 2012.

[16] V. Sankar, V. Hearnden, K. Hull et al., "Local drug delivery for oral mucosal diseases: challenges and opportunities," Oral Diseases, vol. 17, no. 1, pp. 73-84, 2011.

[17] A. M. Avachat, K. N. Gujar, and K. V. Wagh, "Development and evaluation of tamarind seed xyloglucan-based mucoadhesive buccal films of rizatriptan benzoate," Carbohydrate Polymers, vol. 91, no. 2, pp. 537-542, 2013.

[18] J. G. Meher, M. Tarai, N. P. Yadav, A. Patnaik, P. Mishra, and K. S. Yadav, "Development and characterization of cellulosepolymethacrylate mucoadhesive film for buccal delivery of carvedilol," Carbohydrate Polymers, vol. 96, no. 1, pp. 172180, 2013.

[19] V. F. Patel, F. Liu, and M. B. Brown, "Modeling the oral cavity: in vitro and in vivo evaluations of buccal drug delivery systems," Journal of Controlled Release, vol. 161, no. 3, pp. 746-756, 2012. 
[20] K. K. Peh and C. F. Wong, "Polymeric films as vehicle for buccal delivery: swelling, mechanical, and bioadhesive properties," Journal of Pharmacy \& Pharmaceutical Sciences, vol. 2, no. 2, pp. 53-61, 1999.

[21] A. Miro, F. Ungaro, F. Balzano et al., "Triamcinolone solubilization by (2-hydroxypropyl)- $\beta$-cyclodextrin: a spectroscopic and computational approach," Carbohydrate Polymers, vol. 90, no. 3, pp. 1288-1298, 2012.

[22] J. A. Nicolazzo, B. L. Reed, and B. C. Finnin, "Enhancing the buccal mucosal uptake and retention of triamcinolone acetonide," Journal of Controlled Release, vol. 105, no. 3, pp. 240 248, 2005.

[23] R. K. Mishra, A. K. Banthia, and A. B. A. Majeed, "Pectin based formulations for biomedical applications: a review," Asian Journal of Pharmaceutical and Clinical Research, vol. 5, no. 4, 2012.

[24] G. Smistad, S. Bøyum, S. J. Alund, A. B. C. Samuelsen, and M. Hiorth, "The potential of pectin as a stabilizer for liposomal drug delivery systems," Carbohydrate Polymers, vol. 90, no. 3, pp. 1337-1344, 2012.

[25] G. A. Soares, A. D. d. Castro, B. S. F. Cury, and R. C. Evangelista, "Blends of cross-linked high amylose starch/ pectin loaded with diclofenac," Carbohydrate Polymers, vol. 91, no. 1, pp. 135-142, 2013.

[26] M. Ahuja, S. Singh, and A. Kumar, "Evaluation of carboxymethyl gellan gum as a mucoadhesive polymer," International Journal of Biological Macromolecules, vol. 53, pp. 114-121, 2013.

[27] L. Yang, A. T. Paulson, and M. T. Nickerson, "Mechanical and physical properties of calcium-treated gellan films," Food Research International, vol. 43, no. 5, pp. 1439-1443, 2010.

[28] I. B. Bajaj, S. A. Survase, P. S. Saudagar, and R. S. Singhal, "Gellan gum: fermentative production, downstream processing and applications," Food Technology \& Biotechnology, vol. 45, no. 4, pp. 341-354, 2007.

[29] M. Narkar, P. Sher, and A. Pawar, "Stomach-specific controlled release gellan beads of acid-soluble drug prepared by ionotropic gelation method," AAPS PharmSciTech, vol. 11, no. 1, pp. 267-277, 2010.

[30] T. Osmałek, A. Froelich, and S. Tasarek, "Application of gellan gum in pharmacy and medicine," International Journal of Pharmaceutics, vol. 466, no. 1-2, pp. 328-340, 2014.

[31] C. S. F. Picone and R. L. Cunha, "Chitosan-gellan electrostatic complexes: influence of preparation conditions and surfactant presence," Carbohydrate Polymers, vol. 94, no. 1, pp. 695-703, 2013.

[32] F. G. Prezotti, B. S. F. Cury, and R. C. Evangelista, "Mucoadhesive beads of gellan gum/pectin intended to controlled delivery of drugs," Carbohydrate Polymers, vol. 113, pp. 286-295, 2014.

[33] M. W. Lee, H. J. Chen, and S. W. Tsao, "Preparation, characterization and biological properties of Gellan gum films with 1-ethyl-3-(3-dimethylaminopropyl) carbodiimide crosslinker," Carbohydrate Polymers, vol. 82, no. 3, pp. 920-926, 2010.

[34] M. W. Lee, H. F. Tsai, S. M. Wen, and C. H. Huang, "Photocrosslinkable gellan gum film as an anti-adhesion barrier," Carbohydrate Polymers, vol. 90, no. 2, pp. 1132-1138, 2012.

[35] A. Kaur and G. Kaur, "Mucoadhesive buccal patches based on interpolymer complexes of chitosan-pectin for delivery of carvedilol," Saudi Pharmaceutical Journal, vol. 20, no. 1, pp. 21-27, 2012.
[36] R. B. Moreira, J. A. Teixeira, A. M. Furuyama-Lima, N. C. Souza, and A. B. Siqueira, "Preparation, characterization and evaluation of drug-delivery systems: pectin and mefenamic acid films," Thermochimica Acta, vol. 590, pp. 100-106, 2014.

[37] K. Ofori-Kwakye and J. T. Fell, "Biphasic drug release: the permeability of films containing pectin, chitosan and HPMC," International Journal of Pharmaceutics, vol. 226, no. 1-2, pp. 139-145, 2001.

[38] M. Preis, K. Knop, and J. Breitkreutz, "Mechanical strength test for orodispersible and buccal films," International Journal of Pharmaceutics, vol. 461, no. 1-2, pp. 22-29, 2014.

[39] USP, United States Pharmacopeia, United States Pharmacopeia, Washington DC USA, 37th edition, 2015.

[40] N. Ninan, M. Muthiah, I. K. Park, A. Elain, S. Thomas, and Y. Grohens, "Pectin/carboxymethyl cellulose/microfibrillated cellulose composite scaffolds for tissue engineering," Carbohydrate Polymers, vol. 98, no. 1, pp. 877-885, 2013.

[41] A. H. Hazimah, T. L. Ooi, and A. Salmiah, "Recovery of glycerol and diglycerol from glycerol pitch," Journal of Oil Palm Research, vol. 15, no. 1, pp. 1-5, 2003.

[42] U. Einhorn-Stoll, H. Kunzek, and G. Dongowski, "Thermal analysis of chemically and mechanically modified pectins," Food Hydrocolloids, vol. 21, no. 7, pp. 1101-1112, 2007.

[43] A. A. Da Silva-Junior, J. R. de Matos, T. P. Formariz et al., "Thermal behavior and stability of biodegradable spray-dried microparticles containing triamcinolone," International Journal of Pharmaceutics, vol. 368, no. 1-2, pp. 45-55, 2009.

[44] V. S. Pandey, S. K. Verma, M. Yadav, and K. Behari, "Studies on graft copolymerization of gellan gum with $\mathrm{N}, \mathrm{N}$-dimethylacrylamide by the redox system," International Journal of Biological Macromolecules, vol. 70, pp. 108-115, 2014.

[45] M. Preis, C. Woertz, P. Kleinebudde, and J. Breitkreutz, "Oromucosal film preparations: classification and characterization methods," Expert Opinion on Drug Delivery, vol. 10, no. 9, pp. 1303-1317, 2013.

[46] O. B. G. Assis, "Alteração do caráter hidrofílico de filmes de quitosana por tratamento de plasma de hmds," Quimica Nova, vol. 33, no. 3, pp. 603-606, 2010.

[47] P. Walkenström, S. Kidman, A. M. Hermansson, P. B. Rasmussen, and L. Hoegh, "Microstructure and rheological behaviour of alginate/pectin mixed gels," Food Hydrocolloids, vol. 17, no. 5, pp. 593-603, 2003.

[48] L. Whitehead, J. H. Collett, and J. T. Fell, "Amoxycillin release from a floating dosage form based on alginates," International Journal of Pharmaceutics, vol. 210, no. 1-2, pp. 45-49, 2000.

[49] R. C. Mundargi, S. A. Patil, S. A. Agnihotri, and T. M. Aminabhavi, "Evaluation and controlled release characteristics of modified xanthan films for transdermal delivery of atenolol," Drug Development and Industrial Pharmacy, vol. 33, no. 1, pp. 79-90, 2007.

[50] C. L. Silva, J. C. Pereira, A. Ramalho, A. A. C. C. Pais, and J. J. S. Sousa, "Films based on chitosan polyelectrolyte complexes for skin drug delivery: development and characterization," Journal of Membrane Science, vol. 320, no. 1-2, pp. 268-279, 2008.

[51] R. A. Talja, H. Helén, Y. H. Roos, and K. Jouppila, "Effect of various polyols and polyol contents on physical and mechanical properties of potato starch-based films," Carbohydrate Polymers, vol. 67, no. 3, pp. 288-295, 2007.

[52] E. R. Morris, K. Nishinari, and M. Rinaudo, "Gelation of gellan a review," Food Hydrocolloids, vol. 28, no. 2, pp. 373-411, 2012. 
[53] V. Evageliou, R. K. Richardson, and E. R. Morris, "Effect of pH, sugar type and thermal annealing on high-methoxy pectin gels," Carbohydrate Polymers, vol. 42, no. 3, pp. 245-259, 2000.

[54] C. M. Lopes, J. M. S. Lobo, and P. Costa, "Formas farmacêuticas de liberação modificada: polímeros hidrifílicos," Brazilian Journal of Pharmaceutical Sciences, vol. 41, no. 2, pp. 143154, 2005.

[55] B. R. Pezzini, M. A. S. Silva, and H. G. Ferraz, "Formas farmacêuticas sólidas orais de liberação prolongada: sistemas monolíticos e multiparticulados," Brazilian Journal of Pharmaceutical Sciences, vol. 43, no. 4, pp. 491-502, 2007.

[56] C. Maderuelo, A. Zarzuelo, and J. M. Lanao, "Critical factors in the release of drugs from sustained release hydrophilic matrices," Journal of Controlled Release, vol. 154, no. 1, pp. 2-19, 2011.

[57] R. W. Korsmeyer, R. Gurny, E. Doelker, P. Buri, and N. A. Peppas, "Mechanisms of solute release from porous hydrophilic polymers," International Journal of Pharmaceutics, vol. 15, no. 1, pp. 25-35, 1983.

[58] S. Kaity, J. Isaac, and A. Ghosh, "Interpenetrating polymer network of locust bean gum-poly (vinyl alcohol) for controlled release drug delivery," Carbohydrate Polymers, vol. 94, no. 1, pp. 456-467, 2013. 


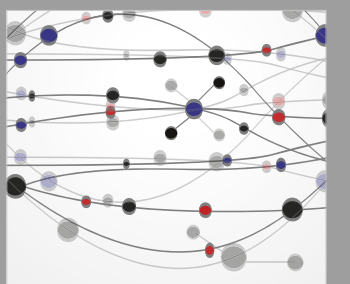

The Scientific World Journal
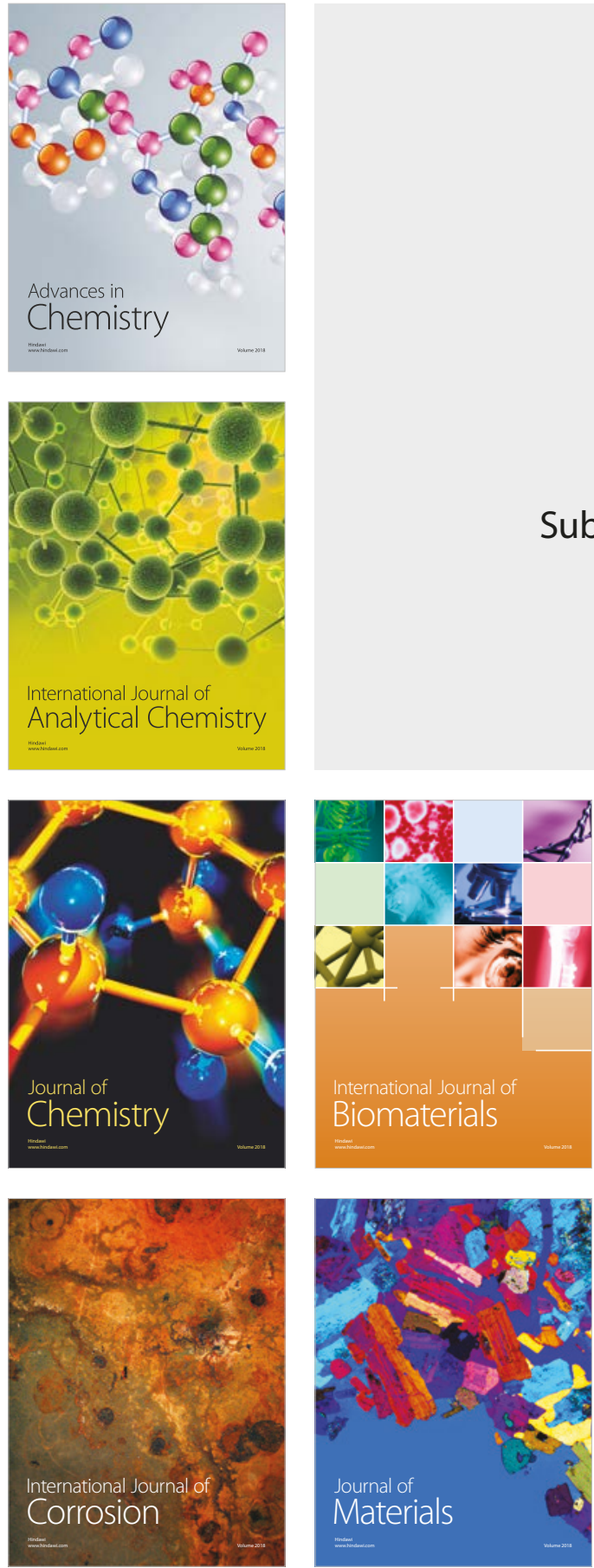

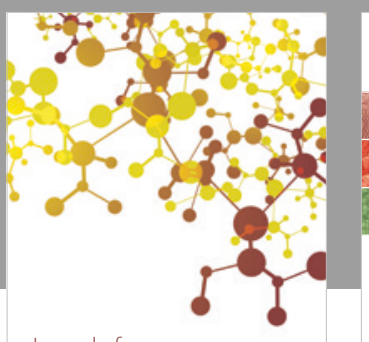

Journal of

Applied Chemistry
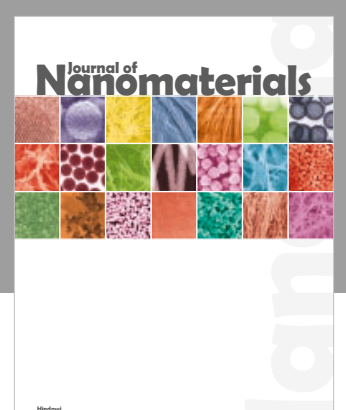

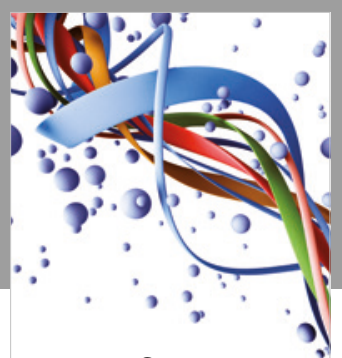

Scientifica

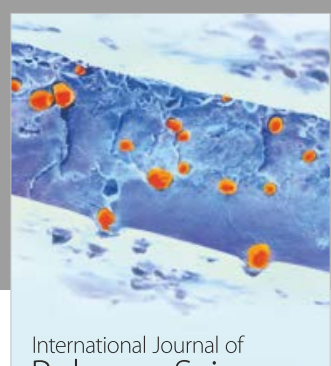

Polymer Science

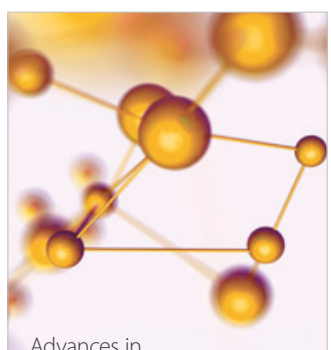

Physical Chemistry
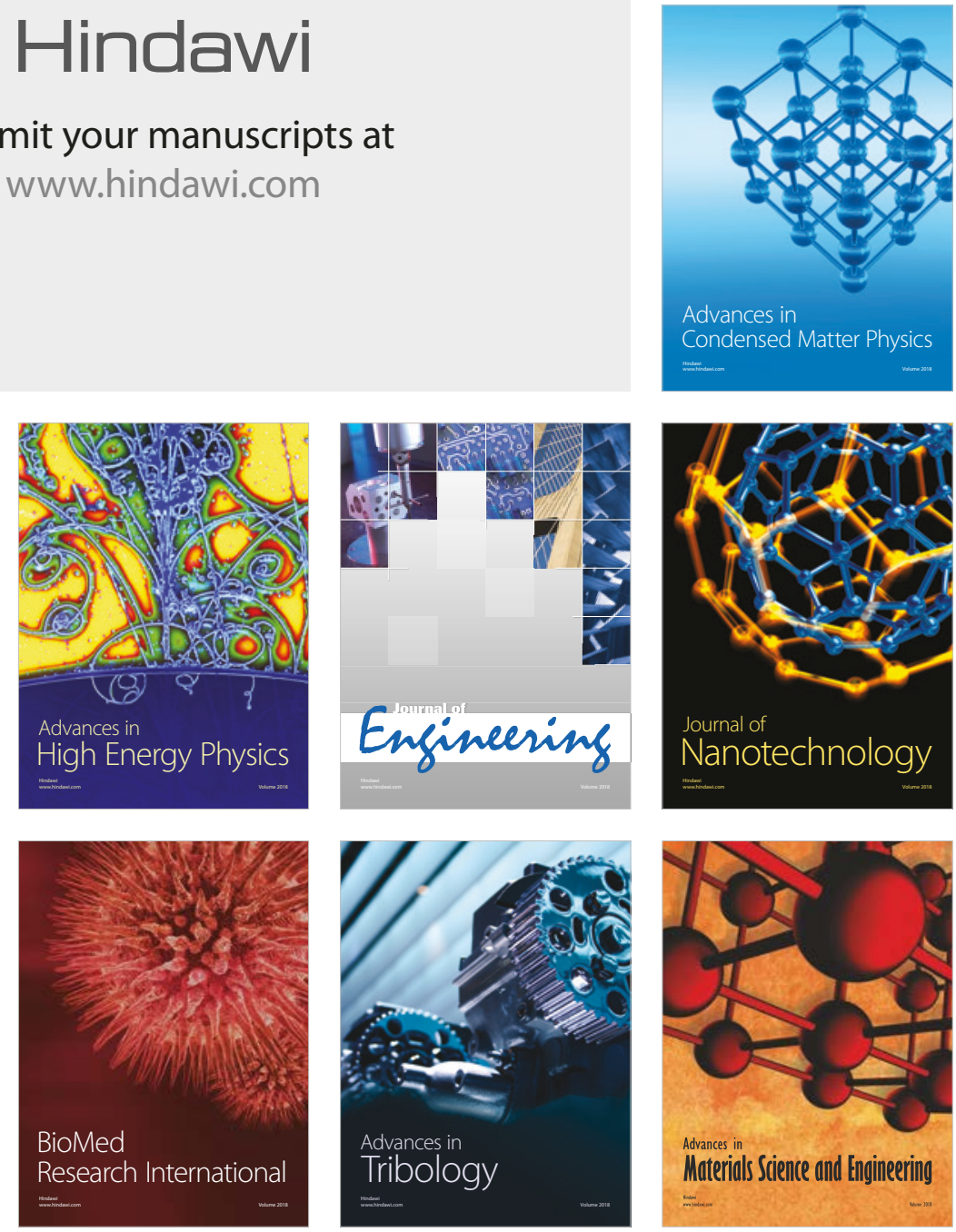